University of Nebraska - Lincoln

DigitalCommons@University of Nebraska - Lincoln

USDA Forest Service / UNL Faculty Publications U.S. Department of Agriculture: Forest Service -National Agroforestry Center

4-2006

\title{
Automated estimation of individual conifer tree height and crown diameter via two-dimensional spatial wavelet analysis of lidar data
}

\author{
Michael J. Falkowski \\ University of Idaho, Falk4587@uidaho.edu \\ Alistair M.S. Smith \\ University of Idaho, alistair@uidaho.edu \\ Andrew T. Hudak \\ Rocky Mountain Research Station, ahudak@fs.fed.us \\ Paul E. Gessler \\ University of Idaho, paulg@uidaho.edu \\ Lee A. Vierling \\ University of Idaho, leev@uidaho.edu \\ See next page for additional authors
}

Follow this and additional works at: https://digitalcommons.unl.edu/usdafsfacpub

Falkowski, Michael J.; Smith, Alistair M.S.; Hudak, Andrew T.; Gessler, Paul E.; Vierling, Lee A.; and Crookston, Nicholas L., "Automated estimation of individual conifer tree height and crown diameter via two-dimensional spatial wavelet analysis of lidar data" (2006). USDA Forest Service / UNL Faculty Publications. 183.

https://digitalcommons.unl.edu/usdafsfacpub/183

This Article is brought to you for free and open access by the U.S. Department of Agriculture: Forest Service -National Agroforestry Center at DigitalCommons@University of Nebraska - Lincoln. It has been accepted for inclusion in USDA Forest Service / UNL Faculty Publications by an authorized administrator of DigitalCommons@University of Nebraska - Lincoln. 


\section{Authors}

Michael J. Falkowski, Alistair M.S. Smith, Andrew T. Hudak, Paul E. Gessler, Lee A. Vierling, and Nicholas L. Crookston 


\title{
Automated estimation of individual conifer tree height and crown diameter via two-dimensional spatial wavelet analysis of lidar data
}

\author{
Michael J. Falkowski, Alistair M.S. Smith, Andrew T. Hudak, \\ Paul E. Gessler, Lee A. Vierling, and Nicholas L. Crookston
}

\begin{abstract}
We describe and evaluate a new analysis technique, spatial wavelet analysis (SWA), to automatically estimate the location, height, and crown diameter of individual trees within mixed conifer open canopy stands from light detection and ranging (lidar) data. Two-dimensional Mexican hat wavelets, over a range of likely tree crown diameters, were convolved with lidar canopy height models. Identification of local maxima within the resultant wavelet transformation image then allowed determination of the location, height, and crown diameters of individual trees. In this analysis, which focused solely on individual trees within open canopy forests, 30 trees incorporating seven dominant North American tree species were assessed. Two-dimensional (2D) wavelet-derived estimates were well correlated with field measures of tree height $(r=0.97)$ and crown diameter $(r=0.86)$. The $2 \mathrm{D}$ wavelet-derived estimates compared favorably with estimates derived using an established method that uses variable window filters (VWF) to estimate the same variables but relies on a priori knowledge of the tree height - crown diameter relationship. The 2D spatial wavelet analysis presented herein could potentially allow automated, large-scale, remote estimation of timber board feet, foliar biomass, canopy volume, and aboveground carbon, although further research testing the limitations of the method in a variety of forest types with increasing canopy closures is warranted.
\end{abstract}

Résumé. Nous décrivons et évaluons une nouvelle technique d'analyse, l'analyse spatiale en ondelettes (ASO) pour estimer automatiquement la localisation, la hauteur et le diamètre de la couronne des arbres individuels dans des peuplements de conifères mixtes à couvert ouvert à partir de données lidar (light detection and ranging). Des ondelettes à deux dimensions de type chapeau mexicain pour une variété de diamètres de couronnes d'arbres potentiels ont été convoluées avec des modèles de hauteur de couvert lidar. L'identification de maximums locaux à l'intérieur de l'image de transformation en ondelettes résultante a permis par la suite la détermination de la localisation, de la hauteur et des diamètres des couronnes des arbres individuels. Dans cette analyse, qui s'est concentrée seulement sur les arbres individuels à l'intérieur de forêts à couvert ouvert, 30 arbres représentant sept espèces dominantes d'arbres d'Amérique du Nord ont été évalués. Les estimations 2-D dérivées des ondelettes étaient bien corrélées avec les mesures de terrain de la hauteur des arbres $(r=0,97)$ et du diamètre de la couronne $(r=0,86)$. Les estimations 2-D dérivées des ondelettes se comparaient avantageusement aux estimations dérivées à l'aide d'une méthode établie utilisant des filtres de fenêtre variable (FFV) pour l'estimation de ces mêmes variables, mais qui est basée sur la connaissance a priori de la relation hauteur des arbres/diamètre de la couronne. L'analyse spatiale en ondelettes 2-D présentée ici pourrait potentiellement permettre l'estimation automatisée à grande échelle par télédétection du pied-planche de bois de sciage, de la biomasse foliaire, du volume du couvert et du carbone aérien, bien que des recherches additionnelles pour tester les limites de la méthode dans divers types de forêts avec des fermetures du couvert croissantes soient nécessaires.

[Traduit par la Rédaction]

\section{Introduction}

There has always existed a need in the remote sensing community for information at the individual plant scale, but researchers have instead relied on broader scale inferences because of limitations in image spatial resolution. High spatial resolution (i.e., $<5 \mathrm{~m}$ equivalent pixel size) structural datasets may provide viable alternatives to such assumptions. For instance, data derived from light detection and ranging (lidar) systems provide canopy information including tree height, canopy height variability, and canopy closure (e.g., Nilsson, 1996; Lefsky et al., 1999; Means et al., 1999; Harding et al., 2001; Naesset and Bjerknes, 2001; Hudak et al., 2002; Holmgren, 2004; Nelson et al., 2004; Anderson et al., 2005).
Aerial photography and other high spatial resolution imagery have been used to automatically detect and measure individual trees through various filtering techniques and textural analysis

Received 29 September 2005. Accepted 24 November 2005.

M.J. Falkowski, ${ }^{1}$ A.M.S. Smith, and P.E. Gessler. Department of Forest Resources, University of Idaho, Moscow, ID 838441133, USA.

A.T. Hudak and N.L. Crookston. Rocky Mountain Research Station, US Department of Agriculture Forest Service, 1221 South Main Street, Moscow, ID 83843, USA.

L.A. Vierling. Department of Rangeland Ecology and Management, University of Idaho, Moscow, ID 83844-1135, USA.

${ }^{1}$ Corresponding author (e-mail: falk4587@uidaho.edu). 
methods (Fournier et al., 1995; Gougeon, 1995; Asner et al., 2003; Wulder et al., 2004). Such techniques determine the location of individual trees by detecting local maxima within an image, where each local maximum corresponds to an individual treetop (Pouliot et al., 2002; Wang et al., 2004). Although such methods can resolve individuals (i.e., provide a map in which single objects can be visually distinguished), they generally do not automatically extract information on each object separately, but rather for the entire thematic collection of objects (e.g., as a cover or stand map). When such methods are used in conjunction with a lidar-derived canopy height model (CHM), however, the detected local maxima correspond to the location and heights of individual trees. The accuracy of tree-detection algorithms (both aerial photography and lidar based) are largely dependent upon the structural complexity of forest stands, with high accuracies attained in open, single-story stands and comparatively lower accuracies in closed multistory stands (Maltamo et al., 2004).

Several studies have also used a combination of lidar with multispectral or hyperspectral data to extract additional individual tree information such as tree crown diameter, tree location, and tree species (e.g., Evans et al., 2001; Popescu et al., 2003; Leckie et al., 2003; Brandtberg et al., 2003; Maltamo et al., 2004; Popescu and Wynne, 2004; Riano et al., 2004; Koukoulas and Blackburn, 2005). Even though lidar has the potential to provide high-precision data at the subcanopy scale, it remains difficult to accurately identify individual tree attributes (Popescu et al., 2003; Anderson et al., 2005), especially in closed or multistory stands. In addition, most traditional filtering methods evaluate features at only one particular operator or kernel size, which is typically selected by the analyst to match the specific application. For example, Wang et al. (2004) implemented a Laplacian of the Gaussian (LoG) filter to delineate isolated trees and clumps of trees from high spatial resolution aerial photography. Although the potential of evaluating multiple operator sizes of LoG was highlighted by Wang et al., the authors did not attempt such an analysis, citing known difficulties associated with integrating LoG results from multiple operator sizes (i.e., Lu and Jain, 1998).

In contrast, recent advances in object-orientated image processing techniques have demonstrated the potential of wavelet analysis to identify and assess individual objects separately over a range of scales (Ulfarsson et al., 2003; Yu and Ekstrom, 2003; Li, 2004; Pajares and de la Cruz, 2004; Strand et al., 2006). Wavelets have proven to be important tools for remote sensing analyses, with previous applications in the areas of image filtering, hyperspectral data analysis, image reconstruction, image registration, texture analysis, data fusion, and feature matching (e.g., Le Moigne et al., 2002; Teggi et al., 2003; Ulfarsson et al., 2003; Sakamoto et al., 2005).

Although over 100 peer-reviewed articles have demonstrated wavelet-based techniques in environmental remote sensing applications, nearly all of these studies employ onedimensional (1D) wavelets, leaving the capabilities of twodimensional (2D) wavelet analyses largely unexplored, with the exception of Ulfarsson et al. (2003), Myint et al. (2004), and Strand et al. (2006).

Recent remote sensing studies that have employed wavelets to identify vegetation structure have continued to follow the welltrodden engineering wavelet paradigm in that they analyze 1D signals (e.g., time series of individual pixels, line samples of sensor imagery, or analysis of hyperspectral pixels separately) rather than investigating the 2D (i.e., image) spatial arrangement of pixel assemblages exhibiting similar or divergent spectral or structural attributes. For example, several studies have used 1D wavelets to analyze hyperspectral pixels to detect soils or individual plant species (Koger et al., 2003; Kempeneers et al., 2005; Zhang et al., 2005). Bradshaw and Spies (1992), Lindsay et al. (1996), and Jordan and Schott (2005) analyzed strips of satellite sensor data to detect forest canopy gaps, surface properties of sea ice, and topographic features. Bruce et al. (2001) and $\mathrm{Li}$ (2004) used 1D wavelets to improve the relative abundance of endmembers for spectral unmixing. Pu and Gong (2004) applied 1D wavelets to individual Hyperion pixels to estimate the leaf area index (LAI) and crown closure. Sakamoto et al. (2005) used 1D wavelets on separate pixels within a moderate-resolution imaging spectroradiometer (MODIS) derived enhanced vegetation index (EVI) time series to isolate seasonal trends.

In contrast, 2D wavelet analysis in remote sensing data has been restricted to matching different image sources for data fusion (Ulfarsson et al., 2003) and image georegistration, although a few studies have employed 2D wavelets to detect buildings within urban areas (e.g., Myint et al., 2004; Vu et al., 2003). Strand et al. (2006) introduced a further application of 2D wavelet analysis that provides information on the spatial location and size (i.e., tree crown diameter) of multipixel-sized trees within a time series of historical aerial photographs. This 2D wavelet analysis technique, which can be applied to any raster dataset, shows considerable promise for objectively and automatically quantifying vegetation structure and biomass, even without yet exploiting the structural dimensionality afforded by lidar data.

In this paper, we assess the utility of this $2 \mathrm{D}$ wavelet analysis method to automatically determine the location, height, and crown diameter of individual trees from a lidar CHM. We compare the results of the 2D wavelet analysis method with those from an established lidar-based tree extraction and measurement technique, developed by Popescu et al. (2003), which implements variable window filters (VWF) to detect and measure individual trees. The accuracy of the lidar-derived individual tree measures (height and crown diameter) from both techniques is then determined through a comparison with field reference measurements.

\section{Methods}

\section{Field sampling}

The study area is located on Moscow Mountain, approximately $9 \mathrm{~km}$ northeast of the city of Moscow in north- 
central Idaho, USA (latitude $46^{\circ} 44^{\prime} \mathrm{N}$, longitude $116^{\circ} 58^{\prime} \mathrm{W}$ ). The forested land is comprised of a mixed conifer forest type that is diverse in both species composition and forest structure. Common conifer species include Pinus ponderosa, Pseudotsuga menziesii, Abies grandis, Thuja plicata, Pinus contorta, Larix occidentalis, and Picea engelmannii.

In a previous study (Falkowski et al., 2005), 83 forest inventory plots were located on Moscow Mountain using a stratified systematic sample design based on elevation, solar insolation, and LAI strata (calculated following Pocewicz et al., 2004). Sampling in such a manner produced spatially irregular plot locations covering the full range of vegetation types and canopy conditions across Moscow Mountain. Plot center positions were precisely recorded with a Trimble ProXR global positioning system (GPS). Following measurement in the field, the GPS data were differentially corrected and averaged to achieve a three-dimensional (3D) point position accurate to within $\pm 0.8 \mathrm{~m}$ horizontally and $\pm 1.1 \mathrm{~m}$ vertically.

Those plots having an open canopy structure were subset $(N=$ 15) for this analysis, because the $2 \mathrm{~m}$ nominal post spacing of the lidar survey could not resolve individual tree crowns in closed canopy conditions. Within each 0.04 ha (radius $=11.35 \mathrm{~m}$ ) fixedradius plot, diameter at breast height $(\mathrm{DBH})$, species, and distance and bearing from plot center (i.e., location) were recorded for every tree or snag $\geq 2.7 \mathrm{~cm} \mathrm{DBH}$. Individual tree height and crown diameter were also measured for each tree within the 15 plots using an Impulse 200 laser rangefinder (Laser Technology Inc., Englewood, Colo.). From the subset of 15 open canopy plots, 30 individual trees could be easily distinguished from the lidar CHM (Figure 1b). Each plot had fewer than 1.4 trees per hectare and an average basal area of $0.54 \mathrm{~m}^{2} / \mathrm{ha}$. The selected trees had a height range of 3.96-40.72 $\mathrm{m}$ (average $=$ $19.84 \mathrm{~m}$ ) and crown diameter range of $2.07-14.55 \mathrm{~m}$ (average = $6.36 \mathrm{~m})$.

\section{Lidar acquisition and processing}

Lidar data (1.95 m nominal post spacing) were acquired in summer 2003 across Moscow Mountain with an ALS40 system (Horizons, Inc., Rapid City, S.Dak.). The system operated at a wavelength of $1064 \mathrm{~nm}$ and was flown at approximately $2500 \mathrm{~m}$ above mean terrain elevation. Once acquired, the lidar data were filtered to remove laser returns with a scan angle greater than $18^{\circ}$. Following Evans and Hudak (2005), the filtered lidar data were then separated into ground and nonground (principally vegetation) returns using a progressive curvature filter (http://forest.moscowfsl.wsu.edu/gems/lidar). A $2 \mathrm{~m}$ digital elevation model (DEM) was created from the identified ground returns using a natural neighbor interpolation algorithm within ArcGIS (ESRI, Redlands, Calif.). Following DEM creation, the height of each nonground lidar return was calculated based on its distance from the DEM surface. A CHM, with a spatial resolution of $0.5 \mathrm{~m}$, was then computed from the nonground lidar returns using the natural neighbor algorithm in ArcGIS.

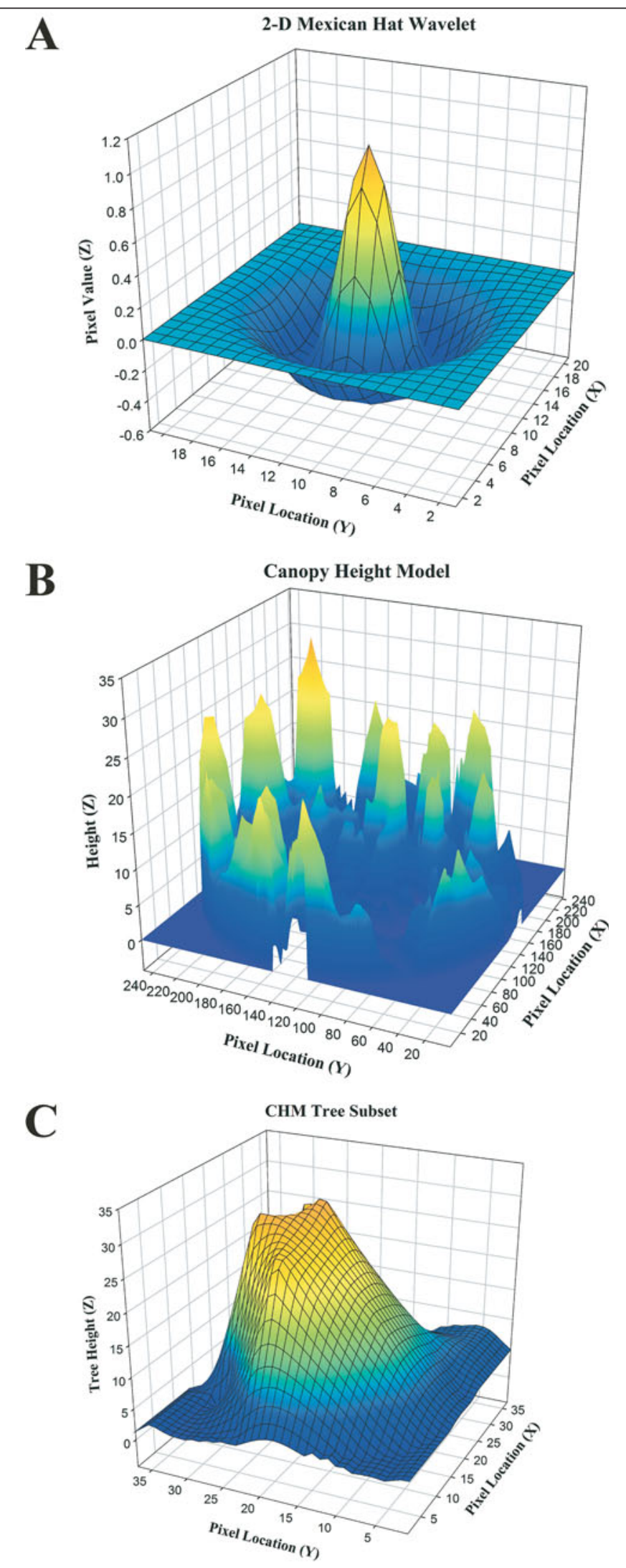

Figure 1. Three-dimensional mesh plots of (A) the twodimensional Mexican hat wavelet, (B) an example canopy height model (CHM), and (C) a single tree subset from the CHM. 


\section{Lidar-based tree height and crown diameter}

Two separate methods were used to automatically detect the location, height, and crown diameter of individual trees from the lidar-derived CHM. The first method is a previously published lidar analysis technique that uses variable-sized windows to detect local maxima (tree heights) within the CHM (Popescu et al., 2003; Popescu and Wynne, 2004), whereas the second method employs 2D wavelet analysis, referred to herein as spatial wavelet analysis (SWA), to measure tree heights and tree crown diameters directly from the CHM.

\section{Variable window filters (VWF)}

The variable window filters (VWF) are a function of the height ( $Z$ value) of each pixel within the CHM and are automatically derived based on empirical relationships between tree height and tree crown diameters. The local maxima within each window correspond to the locations and heights of individual trees. The VWF approach is limited in that it requires a priori knowledge of the tree height - crown diameter relationship; improper specification of this relationship greatly reduces the accuracy of individual tree height estimates. Additionally, weak relationships between tree height and crown diameter will result in inaccurate tree crown diameter estimations.

The VWF algorithm developed by Popescu and Wynne (2004), which is currently coded and executed within the Inter Active Data Language (IDL; Research Systems Inc., 2005), was adapted for the Moscow Mountain study area by modifying the equation it implements to estimate crown diameter from tree height. Unfortunately, on Moscow Mountain the relationship between tree height and crown diameter was weak (Pearson's correlation coefficient $r^{2}=0.34$, root mean square error $($ RMSE $)=1.61 \mathrm{~m})$. This relationship becomes stronger $\left(r^{2}=0.51\right.$, RMSE $\left.=1.30 \mathrm{~m}\right)$ when other field-measured variables (tree species and DBH) are included. Because the VWF algorithm operates solely on the CHM, however, parameters other than height are not included within the crown diameter prediction equation. The modified equation for the Moscow Mountain trees is as follows:

$\mathrm{cd}=2.56+0.14 h$

where cd is the tree crown diameter, and $h$ is the tree height in metres.

\section{Spatial wavelet analysis (SWA)}

The second method used to estimate tree heights and crown diameters from a lidar CHM employs SWA to automatically identify the location $(x, y)$ of each separate tree and estimate individual tree crown diameters and tree heights.

The wavelet transform (WT) is akin to Fourier analysis often used to analyze signals. In Fourier analysis, an infinite signal is decomposed into a series of sine and cosine basis functions over a range of frequencies. For each frequency component, an associated weighting is assigned that represents the contribution to the original signal. Summation of each weighted component allows reconstruction of the original signal. A common application of signal decomposition is denoising, in which the reconstruction occurs after the component due to the frequency (or characteristics feature size) associated with the noise is removed (e.g., Wink and Roerdink, 2004).

In contrast, the WT decomposes signals with finite basis functions, termed wavelets (Addison, 2002). In wavelet analysis, the basic shape of the wavelet, termed the mother function $\{\psi(\lambda)\}$, is dilated over a continuum of scales to produce a series of daughter wavelets, $\left\{\psi_{a, b}(\lambda)\right\}$. This process is described by the following equation:

$\psi_{a, b}(\lambda)=\frac{1}{\sqrt{a}} \psi\left(\frac{\lambda-b}{a}\right)$

where $\lambda$ is the multidimensional location of the center of the daughter wavelet, $a$ is the scaling factor of the function (i.e., dilation scale or frequency), and $b$ is the translation variable (i.e., the parameter responsible for shifting the physical location of the center of the daughter wavelet (Bruce and $\mathrm{Li}$, 2001)). Applying the WT over a range of scales transforms the original signal into a series of outputs that each highlights the scale (i.e., dilation scale) and location of image features (Addison, 2002).

The principal advantage of SWA over traditional filtering methods such as LoG is that the technique is not restricted to analyzing features of a characteristic scale (i.e., often the operator or kernel size). Additionally, SWA is different from other multiscale techniques, such as Gaussian windowed fast Fourier transforms (commonly known as the Gabor Transformation) because, as the wavelet mother function is dilated, the shape of the function (in this paper the 2D Mexican top hat) within the operator is retained. These two characteristics of wavelet analysis allow the assessment of features that have a characteristic shape but do not have a characteristic size (e.g., tree crowns).

Following the methodology of Strand et al. (2006), a series of 2D Mexican hat wavelets (Equation (3); Figure 1a) of progressively larger sizes $(1-15 \mathrm{~m}$, in increments of $0.1 \mathrm{~m}$ ) were convolved with the lidar-derived CHM for each of the 15 plots. The 2D Mexican hat wavelet mother function (Equation (3)) is dilated and shifted across the lidar-derived CHM according to the WT (Equation (2)):

$\psi(x, y)=\left(1-x^{2}-y^{2}\right) \exp \left[-\left(x^{2}+y^{2}\right) / 2\right]$

The Mexican Hat wavelet was chosen because its shape approximates that of individual coniferous trees within a lidarderived canopy height model (Figures 1b and 1c). The wavelet algorithm records three parameters, namely wavelet size (i.e., tree crown diameter), object location $(x, y)$, and a goodness-offit metric (i.e., the weighting of that dilation component). When 
objects within the CHM (i.e., trees or shrubs) are similar in both shape and size to the specific 2D Mexican hat wavelet, a high goodness-of-fit metric is recorded. This metric is normalized by the 2D wavelet size such that inflated goodness-of-fit values are not recorded when both the $2 \mathrm{D}$ wavelet and the image feature are large but not necessarily similar in shape. The $(x, y)$ location of each tree and the 2D wavelet size (i.e., tree crown diameter) associated with the highest goodness-of-fit metric for each separate tree are then recorded in an ASCII file. The 2D wavelet algorithm was coded and executed with Matlab ${ }^{\circledR}$ (The MathWorks Inc., 2004). Further to Strand et al. (2006), the lidar-based SWA approach presented herein provides a measure of tree height in addition to automatically detecting the location and crown diameter of individual trees. This is accomplished by subsetting the CHM by each identified crown diameter. Tree heights are then determined by extracting the maximum height within each subset CHM (see Figure 2 for a graphical representation of this process).

The SWA method does not require a priori information about the stand (i.e., empirical tree height - crown diameter relationships) and has been shown to be effective ( $r=0.96, n=$ 69 ) at measuring the tree crown diameters of western juniper

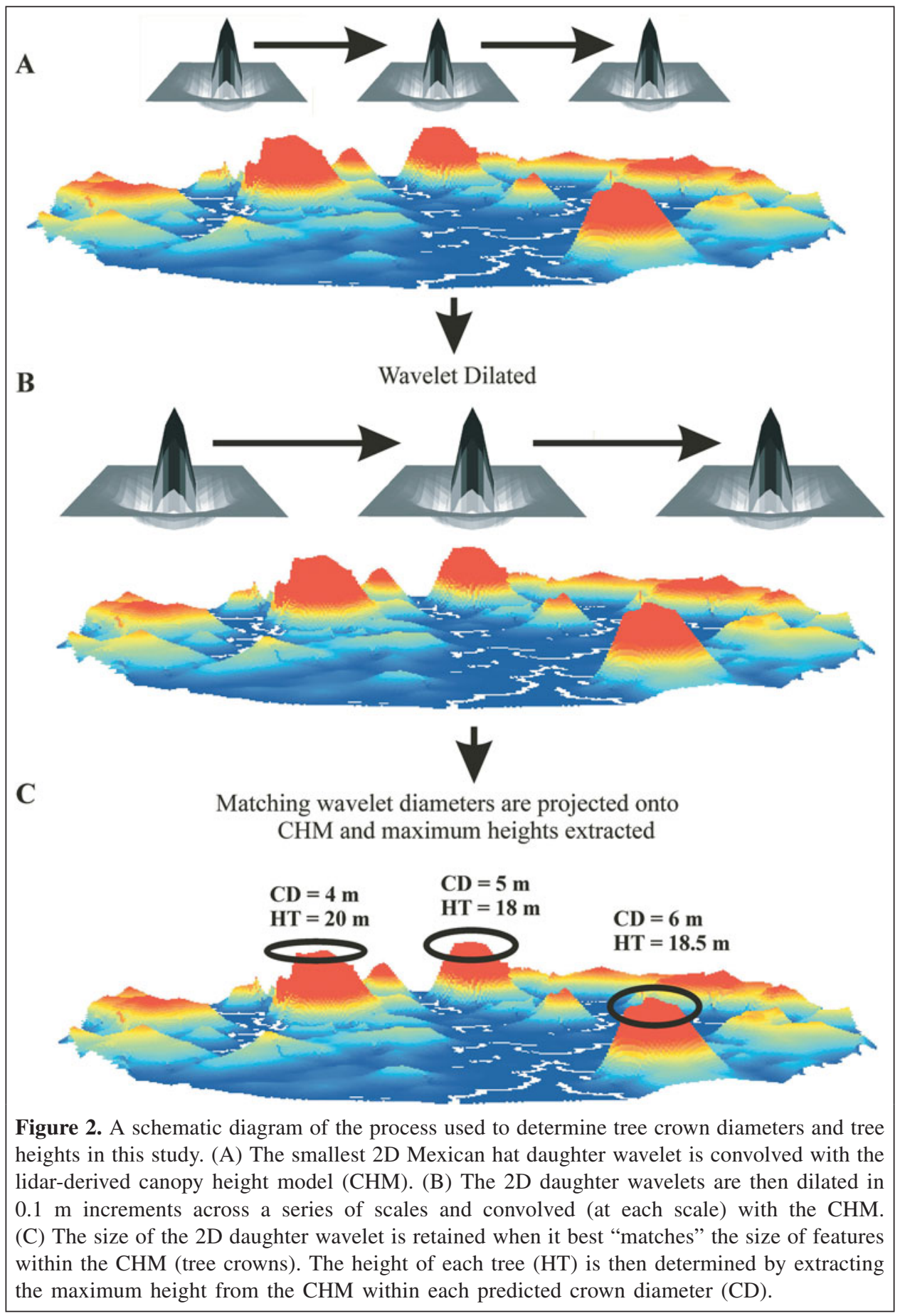


(Juniperus occidentalis) in aerial photographs (Strand et al., 2006). In Strand et al. (2006), the method was applied with an inverted Mexican hat wavelet basis function to evaluate dark objects (juniper trees) on a lighter background (sage-brush and bare soil). Although this indicates that the method could therefore be used to evaluate dark features within the CHM (i.e., canopy gaps), such an application is limited because these features are typically not regular 2D shapes.

\section{Results}

The performance of each tree height and crown width estimation strategy was validated with field-measured tree heights and crown widths and statistically analyzed using root mean square errors (RMSE) and Pearson's correlation coefficients $(r)$. The extraction of individual tree heights from lidar data via the VWF $(\mathrm{R}=0.97, \mathrm{RMSE}=2.81 \mathrm{~m})$ and SWA $(R=0.97, \mathrm{RMSE}=2.64)$ produced similar results. In addition, both VWF and SWA underestimated the height of individual trees (bias $=-6 \%$ and $-4 \%$, respectively) (Table 1; Figure 3). For crown widths, the SWA algorithm produced slightly better results $(R=0.86, \mathrm{RMSE}=1.35 \mathrm{~m})$ than the VWF method $(R=$ $0.79, \mathrm{RMSE}=1.66 \mathrm{~m}$ ) (Table 2; Figure 4). As with tree height estimation, both methods underestimated tree crown widths. SWA was moderately biased $(-7 \%)$, however, whereas the VWF algorithm exhibited a large negative bias $(-15 \%)$.

\section{Discussion and conclusions}

A novel approach to estimating the height and crown diameter of individual trees from lidar data using SWA compared favorably with the previously published VWF approach (Popescu and Wynne, 2004). The difference in RMSEs between methods was only $17 \mathrm{~cm}$, which is small relative to the RMSE. This suggests that individual tree heights in open forest stands can be accurately quantified from lidar data using either technique. The fact that the SWA method does not require a priori knowledge of the tree height - crown diameter relationship, while the VWF method does require this information to work properly, is a clear advantage of the SWA technique is this forest environment. The moderate negative bias associated with lidar-derived tree height estimates was expected because lidar systems typically underestimate tree canopy heights (e.g., Gaveau and Hill, 2003). These underestimates were due to the lower probability that an emitted pulse will strike the top of a tree rather than elsewhere on the tree crown. Additionally, each laser pulse will penetrate tree foliage to some degree before being reflected back to the sensor (Gaveau and Hill, 2003; Maltamo et al., 2004).

For the lidar-based tree crown diameter measures, the SWA technique is superior to the VWF technique. The difference in RMSE between the SWA and VWF techniques was $31 \mathrm{~cm}$, which is high relative to the RMSE. The SWA algorithm produced better estimates of tree crown diameter because it directly measures the size of features within a CHM, rather than
Table 1. Correlation coefficients, root mean square errors (RMSE), and biases between estimated and field-measured tree heights.

\begin{tabular}{lllll}
\hline Method & Correlation & $\begin{array}{l}\text { RMSE } \\
(\mathrm{m})\end{array}$ & Bias & $\begin{array}{l}\% \\
\text { Bias }^{a}\end{array}$ \\
\hline Spatial wavelet analysis & 0.97 & 2.64 & 1.04 & -4 \\
Variable window filter & 0.97 & 2.81 & 1.06 & -6 \\
\hline
\end{tabular}

${ }^{a} \%$ Bias $=1-$ bias.
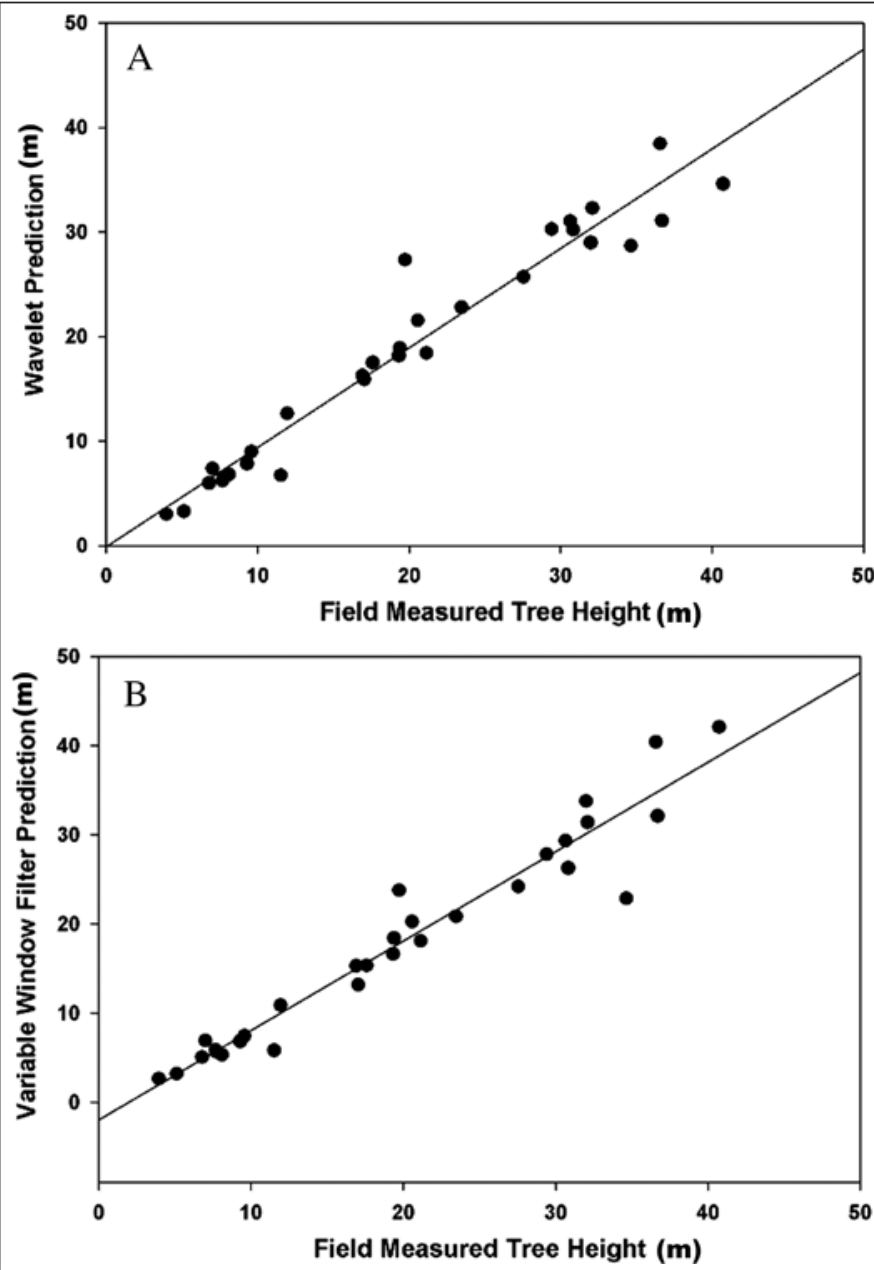

Figure 3. Scatterplots of field-measured tree heights versus tree heights predicted by (A) spatial wavelet analysis (SWA) and (B) variable window filters (VWF).

relying on empirical relationships between tree height and tree crown diameter. Because the relationship between tree height and crown diameter was weak $\left(R^{2}=0.34\right.$, RMSE $\left.=1.61\right)$, the poor performance of the VWF technique was not unexpected. The VWF method could outperform the SWA technique in areas where tree height and crown diameter are strongly related. However, such a case remains to be tested.

The results presented herein suggest that low-density lidar data (e.g., $2 \mathrm{~m}$ post spacing in this analysis) can augment traditional forest inventories in open forest stands by providing reliable remote measures of individual tree heights and crown 
Table 2. Correlation coefficients, root mean square errors, and biases between estimated and field-measured tree crown diameters.

\begin{tabular}{llllc}
\hline Method & Correlation & $\begin{array}{l}\text { RMSE } \\
(\mathrm{m})\end{array}$ & Bias & $\begin{array}{l}\% \\
\operatorname{Bias}^{a}\end{array}$ \\
\hline Spatial wavelet analysis & 0.86 & 1.35 & 1.07 & -7 \\
Variable window filter & 0.79 & 1.66 & 1.15 & -15 \\
\hline a $^{\circ}$ Bias $=1-$ bias
\end{tabular}

${ }^{a} \%$ Bias $=1-$ bias.
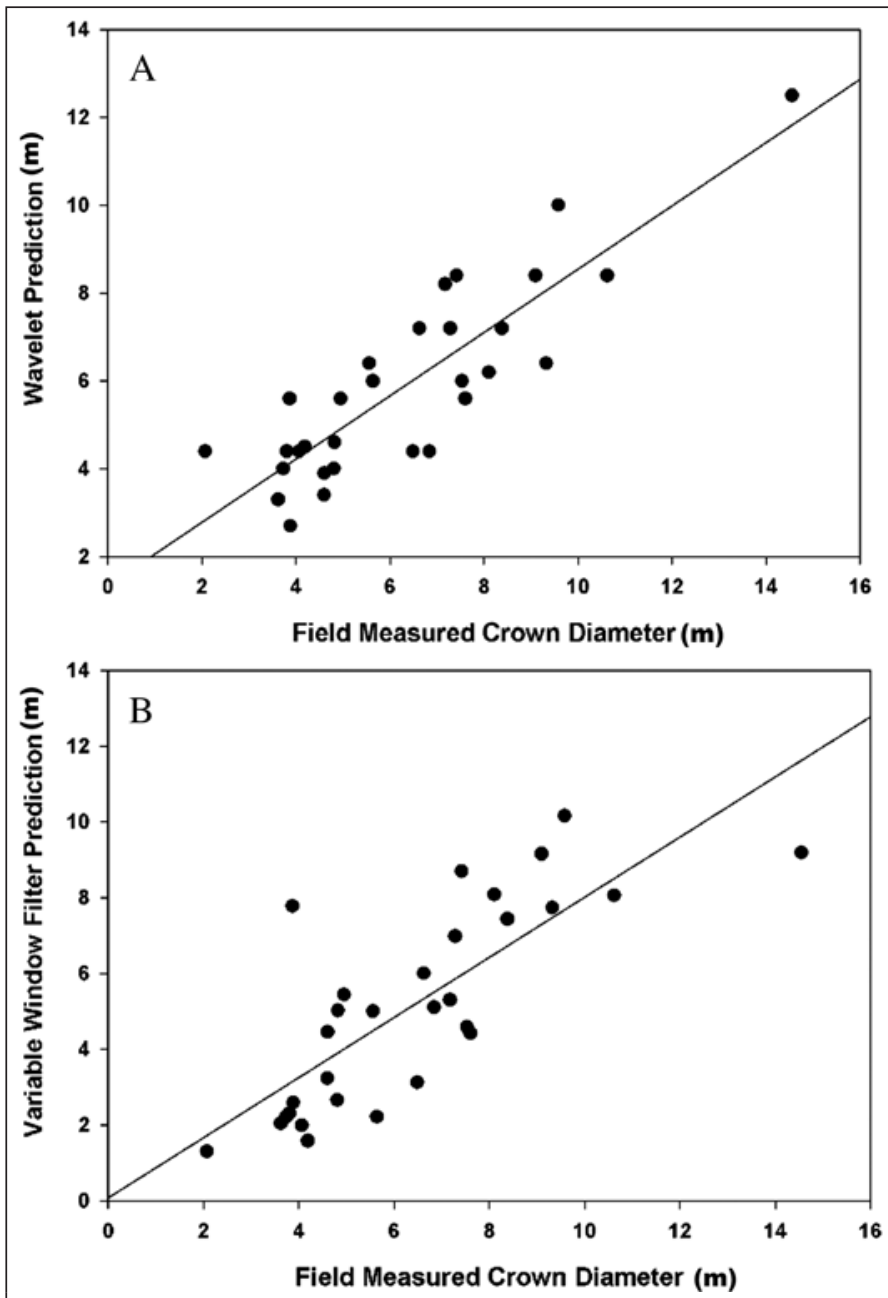

Figure 4. Scatterplots of field-measured tree crown diameters versus tree crown diameters predicted by (A) spatial wavelet analysis (SWA) and (B) variable window filters (VWF).

diameters. The SWA method produced estimates of these variables that either matched or improved upon the estimates derived from the VWF method. The current study only assessed the lidar-based techniques in open forest stands where individual tree crowns could be easily differentiated. The accuracy of most individual tree height extraction methods has been shown to decrease with an increase in canopy closure and tree density (Maltamo et al., 2004). We expect that the same will hold true for lidar-based tree crown diameter estimates. However, further research using higher density lidar data must be conducted to determine the canopy cover or tree density threshold at which these techniques begin to break down and whether such methods are also applicable in other forest types. In evaluating this threshold for individual tree assessment within aerial photography, Strand et al. (2005) has found that such methods fail to accurately detect individuals at canopy covers exceeding $55 \%$. With respect to lidar, this threshold will be dependent on the post spacing of the lidar data, as very dense post-spacing data (i.e., $<1 \mathrm{~m}$ ) are more likely to contain a higher percentage of intracanopy returns and would likely allow improved delineation of neighboring tree crowns. A further issue dependent on adequate post spacing and canopy cover is the influence of edge effects on the SWA-based estimate of crown diameter. Although the edge effects associated with the negative portions present in the 2D wavelet function can be assumed incorporated into the measurement error, data with a small percentage of low height values in the CHM (i.e., dense canopy or high lidar post spacing) will render it more difficult to attain an accurate match between the $2 \mathrm{D}$ Mexican hat wavelet and tree crown shape.

This initial application of lidar-based SWA demonstrates the potential to provide truly "spatial-structural" information on each delineated tree. In a similar manner, SWA could be performed on spectral datasets to provide "spatial-spectral" information on identified image objects. Application of SWA to structural and spectral datasets would then provide information on image objects, rather than the current remote sensing paradigm, in which the spectral information of each pixel within an object is assessed as an independent aspatial observation.

\section{Acknowledgements}

This research was funded through the Sustainable Forestry component of Agenda 2020, a joint effort of the USDA Forest Service Research \& Development and the American Forest and Paper Association. The authors also acknowledge partial funding for this work from the following additional sources: the National Aeronautics and Space Administration (NASA) Synergy program, and the USDA Forest Service Rocky Mountain Research Station (04-JV-11222063-299). Additional funds were also provided by the Forest Public Access Resource Center (ForestPARC), an Upper Midwest Aerospace Consortium (UMAC) group, which is in turn supported with funds from NASA. The authors thank Curtis Kvamme, K.C. Murdock, Jacob Young, Tessa Jones, Jennifer Clawson, Bryn Parker, Kasey Prestwich, Stephanie Jenkins, Kris Poncek, and Jeri Stewart for their assistance in the field. The authors also thank Jeff Evans for the lidar-derived CHM, David Hann for SWA code development, Eric Rowell for his assistance with IDL programming, and anonymous reviewers for their detailed comments on an earlier version of this manuscript.

\section{References}

Addison, P.S. 2002. The illustrated wavelet transform handbook. Institute of Physics Publishing, The Institute of Physics, London, UK. 143 pp. 
Anderson, H.-E., McHaughey, R.J., and Reutebuch, S.E. 2005. Estimating forest canopy fuel parameters using LIDAR data. Remote Sensing of Environment, Vol. 99, pp. 441-449.

Asner, G.P., Archer, S., Hughes, R.F., Ansley, R.J., and Wessman, C.A. 2003. Net change in regional woody vegetation cover and carbon storage in Texas Drylands, 1937-1999. Global Change Biology, Vol. 9, pp. 316-335.

Bradshaw, G.A., and Spies, T.A. 1992. Characterizing canopy gap structure in forests using wavelet analysis. Journal of Ecology, Vol. 80, pp. 205-215.

Brandtberg, T., Warner, T.A., Landenberger, R., and McGraw, J. 2003. Detection and analysis of individual leaf-off tree crowns in small footprint, high sampling density lidar data from the eastern deciduous forest in North America. Remote Sensing of Environment, Vol. 85, pp. 290-303.

Bruce, L.M., and Li, J. 2001. Wavelets for computationally efficient hyperspectral derivative analysis. IEEE Transactions on Geoscience and Remote Sensing, Vol. 39, No. 7, pp. 1540-1546.

Bruce, L.M., Morgan, C., and Larsen, S. 2001. Automated detection of subpixel hyperspectral targets with continuous and discrete wavelet transforms. IEEE Transactions on Geoscience and Remote Sensing, Vol. 39, No. 10, pp. 2217-2226.

Evans, J.S., and Hudak, A.T. 2005. A progressive curvature filter for identifying ground returns from discrete return LiDAR in forested environments. In Lidar Concepts and Resource Applications: Proceedings of the USDA Forest Service Remote Sensing Applications Center Workshop, 17-19 May 2005, Salt Lake City, Utah. CD-ROM. US Department of Agriculture Remote Sensing Applications Center, Salt Lake City, Utah.

Evans, D.L., Roberts, S.D., McCombs, J.W., and Harrington, R.L. 2001. Detection of regularly spaced targets in small-footprint lidar data: research issues for consideration. Photogrammetric Engineering \& Remote Sensing, Vol. 67, pp. 1133-1136.

Falkowski, M.J., Gessler, P.E., Morgan, P., Hudak, A.T., and Smith, A.M.S. 2005. Characterizing and mapping forest fire fuels using ASTER imagery and gradient modeling. Forest Ecology and Management, Vol. 217, Nos. 23, pp. 129-146.

Fournier, R.A., Edwards, G., and Eldridge, N.R. 1995. A catalogue of potential spatial discriminators for high spatial resolution digital images of individual crowns. Canadian Journal of Remote Sensing, Vol. 21, pp. 285298.

Gaveau, D.L.A., and Hill, R.A. 2003. Quantifying canopy height underestimation by laser pulse penetration in small-footprint airborne laser scanning data. Canadian Journal of Remote Sensing, Vol. 29, No. 5, pp. 650-657.

Gougeon, F.A. 1995. Comparison of possible multispectral classification schemes for tree crowns individually delineated on high spatial resolution MEIS images. Canadian Journal of Remote Sensing, Vol. 21, No. 1, pp. 1-9.

Harding, D.J., Lefsky, M.A., Parker, G.G., and Blair, J.B. 2001. Laser altimeter canopy height profiles — methods and validation for closedcanopy, broadleaf forests. Remote Sensing of Environment, Vol. 76, pp. 283-297.

Holmgren, J. 2004. Prediction of tree height, basal area and stem volume in forest stands using airborne laser scanning. Scandinavian Journal of Forest Research, Vol. 19, pp. 543-553.

Hudak, A.T., Lefsky, M.A., Cohen, W.B., and Berterretche, M. 2002. Integration of lidar and Landsat ETM plus data for estimating and mapping forest canopy height. Remote Sensing of Environment, Vol. 82, pp. 397416.
Jordan, G., and Schott, B. 2005. Application of wavelet analysis to the study of spatial pattern of morphotectonic lineaments in digital terrain models. A case study. Remote Sensing of Environment, Vol. 94, pp. 3-38.

Kempeneers, P., De Backer, S., Debruyn, W., Coppin, P., and Scheunders, P. 2005. Generic wavelet-based hyperspectral classification applied to vegetation stress-detection. IEEE Transactions on Geoscience and Remote Sensing, Vol. 43, No. 3, pp. 610-614.

Koger, C., Bruce, L., Shaw, D., and Reddy, K. 2003. Wavelet analysis of hyperspectral reflectance data for detecting pitted morning glory (Ipomoea iacunosa) in soyabean (Glycine max). Remote Sensing of Environment, Vol. 86, pp. 108-119.

Koukoulas, S., and Blackburn, G.A. 2005. Mapping individual tree location, height and species in broadleaved deciduous forest using airborne LIDAR and multi-spectral remotely sensed data. International Journal of Remote Sensing, Vol. 26, pp. 431-455.

Leckie, D., Gougeon, F., Hill, D., Quinn, R., Armstrong, L., and Shreenan, R. 2003. Combined high-density lidar and multispectral imagery for individual tree crown analysis. Canadian. Journal of Remote Sensing, Vol. 29, No. 5, pp. 633-649.

Lefsky, M.A., Harding, D., Cohen, W.B., Parker, G., and Shugart, H.H. 1999. Surface lidar remote sensing of basal area and biomass in deciduous forests of eastern Maryland, USA. Remote Sensing of Environment, Vol. 67, pp. 83-98.

Le Moigne, J., Campbell, W.J., and Cromp, R.F. 2002. An automated parallel image registration technique based on the correlation of wavelet features. IEEE Transactions on Geoscience and Remote Sensing, Vol. 40, No. 8, pp. 1849-1864.

Li, J. 2004. Wavelet-based feature extraction for improved endmember abundance estimation in linear unmixing of hyperspectral signals. IEEE Transactions on Geoscience and Remote Sensing, Vol. 42, pp. 644-649.

Lindsay, R.W., Percival, D.B., and Rothrock, D.W. 1996. Discrete wavelet transform and the scale analysis of the surface properties of sea ice. IEEE Transactions on Geoscience and Remote Sensing, Vol. 34, No. 3, pp. 771-787.

Lu, Y., and Jain, R.C. 1989. Behavior of edges in scale space. IEEE Transactions on Pattern Analysis and Machine Intelligence, Vol. 11, No. 4, pp. 337-356.

Maltamo, M., Mustonen, K., Hyyppa, J., and Yu, X. 2004. The accuracy of estimating individual tree variables with airborne laser scanning in a boreal nature reserve. Canadian Journal of Forest Research, Vol. 34, pp. 17911801.

Means, J.E., Acker, S.A., Harding, D.J., Blair, J.B., Lefsky, M.A., Cohen, W.B., Harmon, M.E., and McKee, W.A. 1999. Use of large-footprint scanning airborne lidar to estimate forest stand characteristics in the Western Cascades of Oregon. Remote Sensing of Environment, Vol. 67, pp. 298-308.

Myint, S.W., Lam, N.S.N., and Tyler, J.M. 2004. Wavelets for urban spatial feature discrimination: comparisons with fractal, spatial autocorrelation, and spatial co-occurrence approaches. Photogrammetric Engineering \& Remote Sensing, Vol. 70, pp. 803-812.

Naesset, E., and Bjerknes, K.O. 2001. Estimating tree heights and number of stems in young forest stands using airborne laser scanner data. Remote Sensing of Environment, Vol. 78, pp. 328-340.

Nelson, R., Short, A., and Valenti, M. 2004. Measuring biomass and carbon in Delaware using airborne profiling LIDAR. Scandinavian Journal of Forest Research, Vol. 19, pp. 500-511. 
Nilsson, M. 1996. Estimation of tree heights and stand volume using an airborne lidar system. Remote Sensing of Environment, Vol. 56, pp. 1-7.

Pajares, G., and de la Cruz, J.M. 2004. A wavelet-based image fusion tutorial. Pattern Recognition, Vol. 37, pp. 1855-1872.

Pocewicz, A.L., Gessler, P.E., and Robinson, A.P. 2004. The relationship between effective plant area index and Landsat spectral response across elevation, solar insolation, and spatial scales, in a northern Idaho forest. Canadian Journal of Forest Research, Vol. 34, No. 2, pp. 465-480.

Popescu, S.C., and Wynne, R.H. 2004. Seeing the trees in the forest: using lidar and multispectral data fusion with local filtering and variable window size for estimating tree height. Photogrammetric Engineering \& Remote Sensing, Vol. 70, pp. 589-604.

Popescu, S.C., Wynne, R.H., and Nelson, R.F. 2003. Measuring individual tree crown diameter with lidar and assessing its influence on estimating forest volume and biomass. Canadian Journal of Remote Sensing, Vol. 29, No. 5, pp. 564-577.

Pouliot, D.D., King, D.J., Bell, F.W., and Pitt, D.G. 2002. Automated tree crown detection and delineation in high-resolution digital camera imagery of coniferous forest regeneration. Remote Sensing of Environment, Vol. 82, pp. 322-334.

Pu, E., and Gong, P. 2004. Wavelet transform applied to EO-1 hyperspectral data for forest LAI and crown closure mapping. Remote Sensing of Environment, Vol. 91, pp. 212-234.

Research Systems Inc. 2005. IDL version 4.0. Research Systems Inc., Boulder, Colo. Available from http://www.rsinc.com.

Riano, D., Chuvieco, E., Condis, S., Gonzalez-Matesanz, J., and Ustin, S.L. 2004. Generation of crown bulk density for Pinus sylvestris from LIDAR. Remote Sensing of Environment, Vol. 92, pp. 345-352.

Sakamoto, T., Yokozawa, M., Toritani, H., Shibayama, M., Ishituka, N., and Ohno, H. 2005. Crop phenology detection method using time-series MODIS data. Remote Sensing of Environment, Vol. 96, pp. 366-374.

Strand, E.K., Vierling, L.A., Smith, A.M.S., Bunting, S.C., Hann, D.B., and Gessler, P.E. 2005. Wavelet estimation of plnt spatial patterns in multitemporal aerial photograph. Eos, Transactions, American Geohpysical Union, Vol. 86, No. 52, Fall Meeting Suppl., Abstract B43B-0287.

Strand, E.K., Smith, A.M.S., Bunting, S.C., Vierling, L.A., Hann, D.B., and Gessler, P.E. 2006. Wavelet estimation of plant spatial patterns in multitemporal aerial photography. International Journal of Remote Sensing. In press. doi: 10.1080/01431160500444764.

Teggi, S., Cecchi, R., and Serafini, F. 2003. TM and IRS-1C-PAN data fusion using multiresolution decomposition methods based on the 'a trous' algorithm. International Journal of Remote Sensing, Vol. 24, No. 6, pp. 1287-1301.

The MathWorks Inc. 2004. Matlab ${ }^{\circledR}$ \& Simulink ${ }^{\circledR}$, version 7.0.0.27 (R14). The MathWorks Inc., Natick, Mass. Available from http://www.mathworks. com/products/matlab/.

Ulfarsson, M.O., Benediktsson, J.A., and Sveinsson, J.R. 2003. Data fusion and feature extraction in the wavelet domain. International Journal of Remote Sensing, Vol. 24, No. 20, pp. 3933-3945.

Vu, T.T., Tokunaga, M., and Yamazaki, F. 2003. Wavelet-based extraction of building features from airborne laser scanning data. Canadian Journal of Remote Sensing, Vol. 29, No. 6, pp. 783-791.
Wang, L., Gong, P., and Biging, G.S. 2004. Individual tree-crown delineation and treetop detection in high-spatial-resolution aerial imagery. Photogrammetric Engineering \& Remote Sensing, Vol. 70, pp. 351-357.

Wink, A.M., and Roerdink, J.B.T.M. 2004. Denoising functional MR images: A comparison of wavelet denoising and Gaussian smoothing, IEEE Transactions on Medical Imaging, Vol. 23, No. 3, pp. 374-387.

Wulder, M.A., White, J.C., Niemann, K.O., and Nelson, T. 2004. Comparison of airborne and satellite high spatial resolution data for the identification of individual trees with local maxima filtering. International Journal of Remote Sensing, Vol. 25, pp. 2225-2232.

Yu, J., and Ekstrom, M. 2003. Multispectral image classification using wavelets: a simulation study. Pattern Recognition, Vol. 36, pp. 889-898.

Zhang, Z., Younan, N.H., and O'Hara, C.G. 2005. Wavelet domain statistical hyperspectral soil texture classification. IEEE Transactions on Geoscience and Remote Sensing, Vol. 43, No. 3, pp. 615-618. 